\title{
APPLICATION DEVELOPMENT FOR ACADEMIC QUEUE MANAGEMENT (FIFO)
}

\section{${ }^{1}$ Jefferson Cardoso Mota, ${ }^{1}$ Rogerio Rodrigues da Silva, ${ }^{1}$ Bruno Pereira Gonçalves, ${ }^{2}$ Benevaldo Pereira Gonçalves, ${ }^{1}$ Jean Mark Lobo de Oliveira and ${ }^{3}$ David Barbosa de Alencar}

\author{
${ }^{1}$ Engineering Department of FAMETRO University Center, Amazon-Brazil \\ ${ }^{2}$ Federal Institute of Educational, Science and Technology of Amazonas - IFAM, Brazil \\ ${ }^{3}$ Institute of Technology and Education Galileo of Amazon (ITEGAM), Brazil
}

\section{ARTICLE INFO}

\section{Article History:}

Received $17^{\text {th }}$ December, 2019

Received in revised form

$23^{\text {rd }}$ January, 2020

Accepted $02^{\text {nd }}$ February, 2020

Published online $31^{\text {st }}$ March, 2020

\section{Key Words:}

Academic Institution; Queue monitoring; Waiting time; smartphones; Justin mind.

\section{*Corresponding author:}

Jefferson Cardoso Mota,

\begin{abstract}
This article describes a quantitative research carried out with students from an academic institution in the city of Manaus-AM. Starting from the hypothesis of the time that students are waiting in a queue at a secretariat. Bearing in mind that in the present times the Information Technology is in an increasing evolution, where the mobile means of communication such as smartphones and the internet connection are extremely accessible by the population, thinking about this scope and the solution of this problem that is common to society in general. We intend to analyze the following question: the need to be in person in electronic queues and through this analysis to develop an application for the management of academic queues. To make this possible, we conducted a research through a tool called Justin mind, taking into account its easy handling for creating prototypes of web applications and mobile devices. The research is based on answering the following questions: regarding the application's proposal; what is the main problem faced by the participants when they arrive at an establishment, in relation to the time that the participants usually spend in line, regarding the use of the application in the academic environment, in relation to the desire to perform other activities while waiting in line. To check the feasibility of the application, the Google Forms platform was used, with the objective of knowing the public's opinion regarding the application's proposal and asking some questions directed to the needs that the application intends to solve. Taking into account all the data analyzed during the research. The application to be developed aims to allow the monitoring of the queue by the user through his mobile device. That way he does not necessarily need to be in the queue so he can carry out other activities, but always following the progress of the queue.
\end{abstract}

Copyright (C) 2020, Jefferson Cardoso Mota et al. This is an open access article distributed under the Creative Commons Attribution License, which permits unrestricted use, distribution, and reproduction in any medium, provided the original work is properly cited.

Citation: Jefferson Cardoso Mota, Rogerio Rodrigues da Silva, Bruno Pereira Gonçalves et al. 2020. “Application development for academic queue management (FIFO)", International Journal of Development Research, 10, (03), 34631-34635.

\section{INTRODUCTION}

The article deals with the development of an application for the management of academic queues, in order to facilitate the student's life, regarding the time spent in queues. The justification for carrying out this work was the need for an application that performed this type of service, something that was different. Thinking about it, the team started the development of the FIFO application, the name itself refers to a concept of information technology regarding the type of scheduling that is used in the application for the process queue, where the processes are executed sequentially, the first process being enters the queue for execution is the first to leave. The development of this application was proposed, which represents this concept in practice. One of the main problems in the academic areas is the delay in attending, causing many students to end up wasting time in queues. The time spent in line (usually 30 minutes to 1 hour) could be better spent and more comfortable, outside the waiting room, both for a student who does not want to miss class time or for those who would like to eat something or go to the bathroom. Nowadays smartphones and internet connection are extremely accessible. Thinking about this scope and the resolution of problems common to society. We intend to solve the following: the need to be in person in electronic queues. The purpose of the application is to allow the user to monitor the queue via the smartphone. That way, he would not need to be present in the queue, he may be following the progress while performing another activity, making the time better spent. Before the start 
of development, it would be necessary to prepare a questionnaire to find out what would be the public's acceptance of this proposal.

\section{MATERIALS AND METHODS}

A search was made to see a platform for creating screens for the application presented here, the Justin Mind application was used, both for its ease of use and the platforms where the screens can be made. First, we created a new prototype on Justin Mind to start creating the screens.

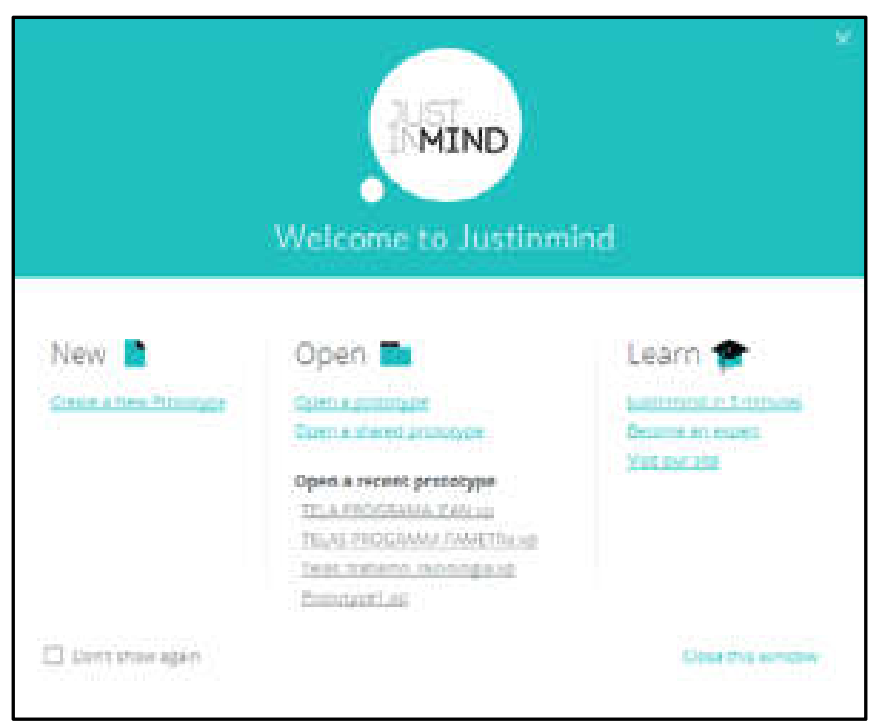

Figure 1. Home screen

Then, we chose on which type of platform the screens would be prototype and the iPhone platform was chosen because it is widely used in university centers.

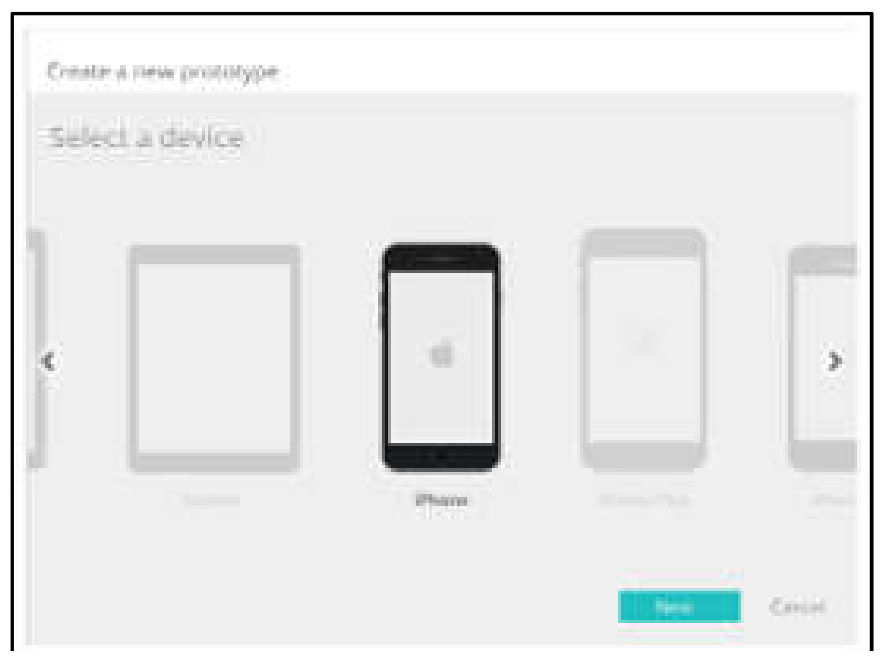

Figure 2. Select Device

The type of orientation we wanted to choose was Portrait. A method used to create the screens of the application was the color palette, in order to be aware of the meanings of the colors used, we ended up opting for the light blue that has as one of the meanings tranquility and the gray color that represents wisdom and stability. The first part in creating the screens was the development of the logo, where there is an image of three people in an order, giving the meaning of being a row, the colors mentioned above were used in the logo image and the name of the FIFO application below, when attaching the logo, a field was attached for the user to put the code that will be generated by the queue attendant that the user wants. The Adobe Illustrator program was used as a tool to create and vectorize the logo used in the application. The name of the application was inspired by the data structure of the queue type, its name FIFO is an acronym in English for First in First out.

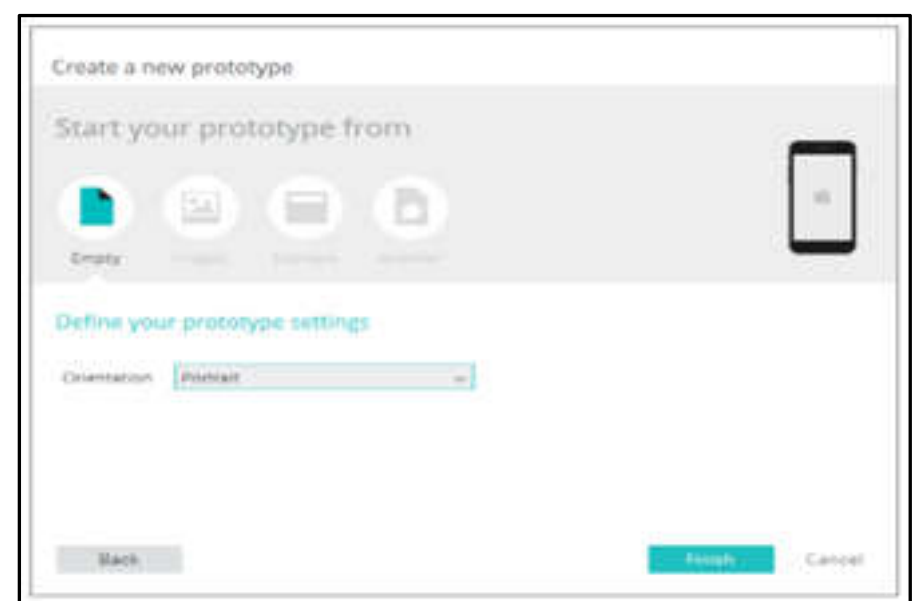

Figure 3. Create a new prototype

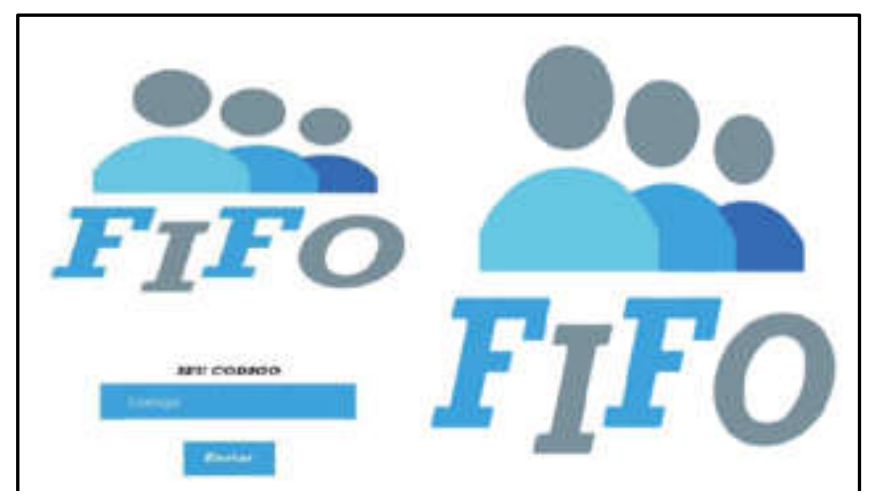

Figure 4. Name of application

The second screen is when the user places the code of his queue, thus, the screen shows his position in the queue and keeps updating for the user to be aware of his turn, thus, allowing the person not to just stay in the waiting place.

\section{SECRETARÍA}

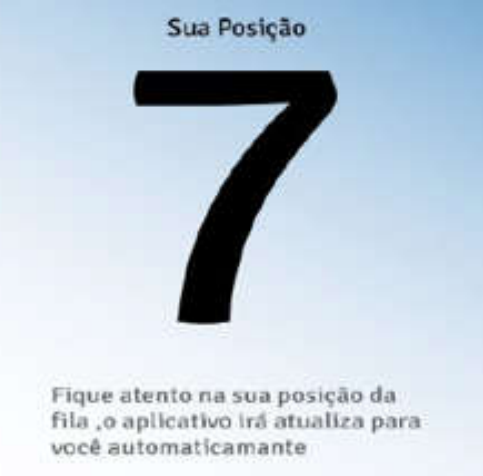

Figure 5. Dialog box 
The dialogues should not contain irrelevant or rarely needed information. Each extra unit of information in a dialogue competes with the relevant units of information and decreases their relative visibility. Based on this we created an interface that was intuitive, something simple, that was easy to use by the user, with only relevant information. That's why we prefer not to fill the screen with too much information so as not to pollute the user's vision.

\section{RESULTS}

To check the feasibility of the application, the Google Forms platform was used, in order to know the public's opinion regarding the application's proposal and questions were asked directed to the needs that the application intends to solve. In total 60 people participated in the survey.

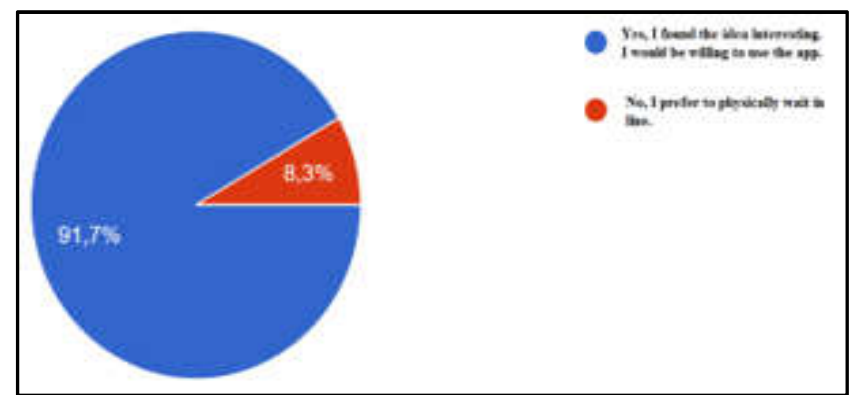

Figure 6. Regarding the application proposal

It was found that $91.7 \%$ of the participants found the idea interesting and would be willing to use the application, while $8.3 \%$ preferred to be physically present in the queue, dispensing with the use of the application.

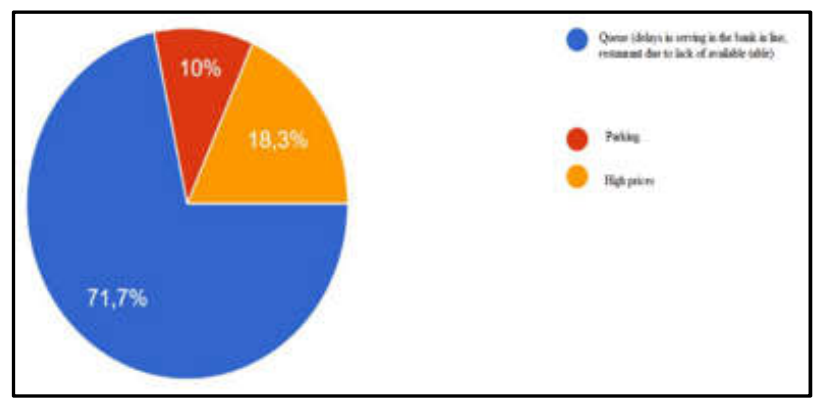

Figure 7. Regarding the main problem faced by participants when arriving at an establishment

It was found that $71.7 \%$ of the participants have the queue as the main problem when they arrive at an establishment (bank, lottery, college etc.), $10 \%$ feel difficult in relation to the demand for parking and to conclude $18.3 \%$ claim that high product prices are a major problem when attending a restaurant or institution.

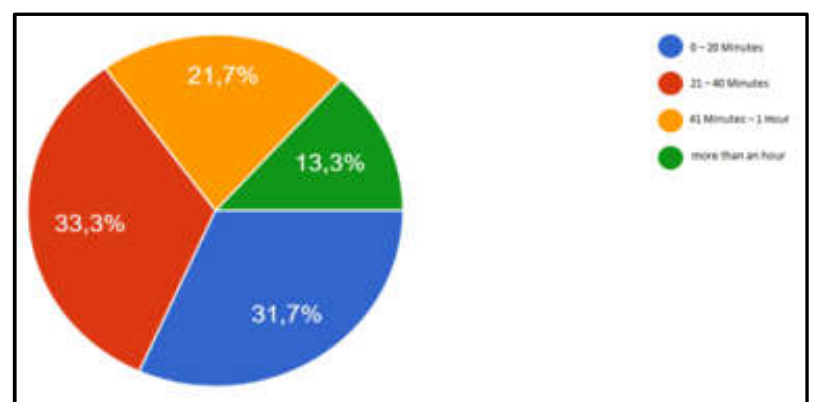

Figure 8. Regarding the time that participants usually spend in line
It was found that $31.7 \%$ of the participants wait up to 20 minutes for the queued service, $33.3 \%$ wait in the queue between 21 to 40 minutes, $21.7 \%$ stay between 41 minutes at one hour, while $13.3 \%$ spend more than an hour waiting for assistance.

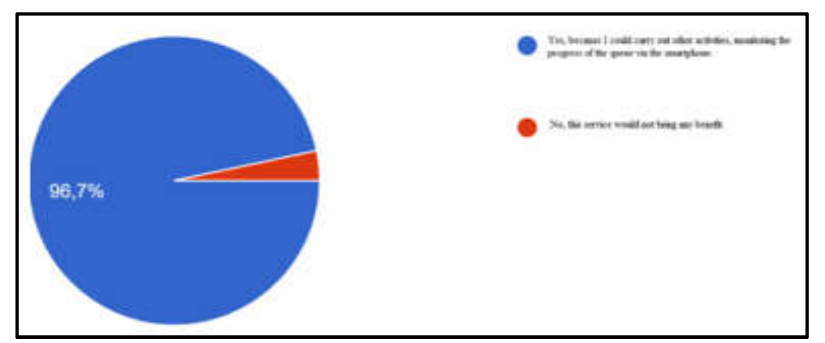

Figure 9. Regarding the use of the application in the academic environment, it would benefit the user

It was found that $96.7 \%$ of participants would use the application in the academic environment, so they could perform other activities monitoring the progress of the queue, while $3.3 \%$ claim that this service would not bring any benefit.

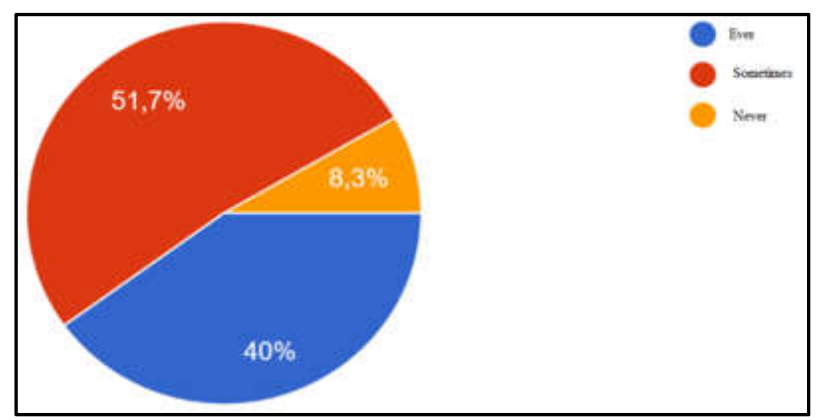

Figure 10. Regarding the desire to perform other activities (eating, going to the bathroom, etc.) while waiting in line

It was found that $51.7 \%$ of participants always feel like doing some activity while waiting in line, $40 \%$ claim that sometimes they are interested in doing another task and to complete $8.3 \%$ they never felt like doing another activity for a while the waiting.

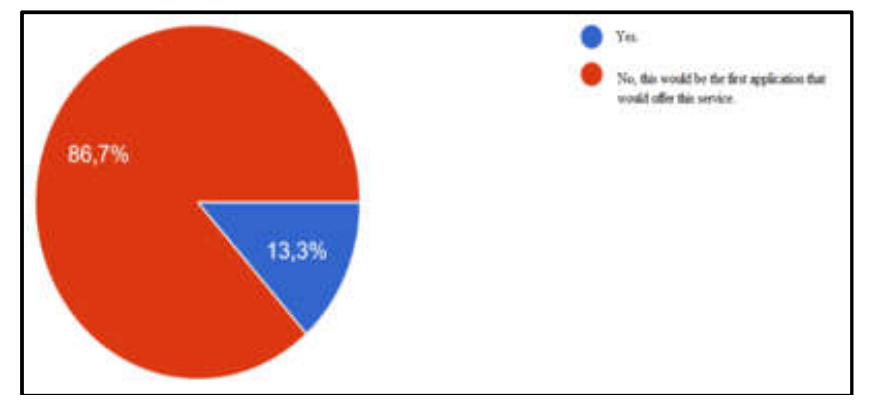

Figure 11. With respect to applications that offer this type of service

It was found that $86.7 \%$ of the participants never saw any application that offered this type of service, while $13.3 \%$ had already observed an application that presented the same proposal. An intuitive interface was developed, which is easy to use by the user, taking into account the usability of the application. The application will only have 2 screens. The first is where the user would place the code that will be generated by the queue attendant that the user wants, in the blue rectangle. When clicking on the "Send" option, it will be 
automatically directed to the next screen that will show the user's position in the queue, containing their position number.

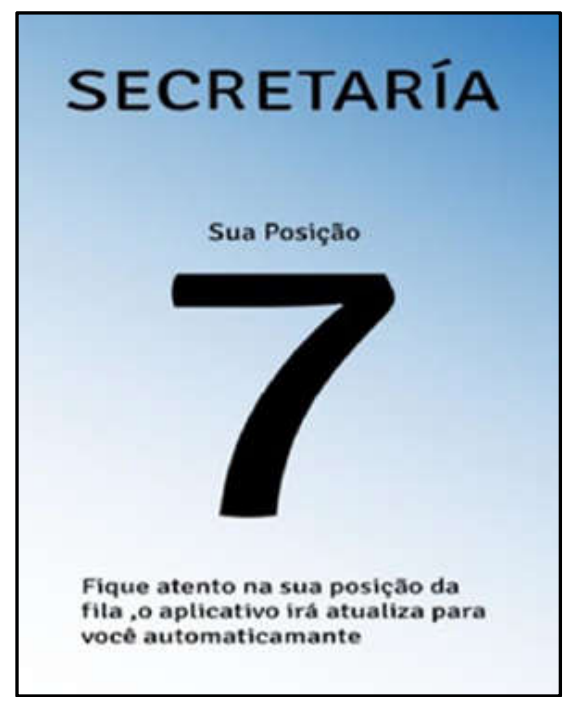

Figure 12. Queue information interface

The application will update the queue position automatically, thus avoiding possible inconvenience regarding the application proposal.

\section{DISCUSSION OF RESULTS}

In this stage of discussion of the results where the research is based on answering some questions such as: the application's proposal, regarding the main problem faced by the participants on arrival at an establishment, in relation to the time that the participants usually spend in line, regarding the use of the application in the academic environment, regarding the desire to perform other activities (eating, going to the bathroom, etc.) while waiting in line, regarding applications that offer this type of service. The following survey had a sample of 60 participants, where $91.7 \%$ found the idea interesting and would be willing to use the application, while $8.3 \%$ would not use the application, preferring to wait in line. There was a great acceptance of the application's proposal to make people's lives easier with regard to the time spent in queues. It was observed in Graph 2 that $71.7 \%$ of the participants have the queue as the main problem when they arrive at an establishment (bank, lottery, college, etc.), $10 \%$ have difficulty regarding the search for parking and to finish $18,3 \%$ claim that high product prices are a major problem when attending a restaurant or institution. Based on this graph it can be seen that, although there are several problems when going to an establishment such as: difficulty in finding parking, high price of the products offered, it is concluded that waiting in line is still a recurring problem of everyday life of most people, so creating an app in that segment would reach a wide audience.

Graph 3 is related to the time that participants usually spend in a queue. It was found that $31.7 \%$ of the participants wait up to 20 minutes for the queued service, $33.3 \%$ wait in the queue between 21 to 40 minutes, $21.7 \%$ stay between 41 minutes at one hour, while $13.3 \%$ spend more than an hour waiting for assistance. It was observed that the time spent waiting in a queue by most participants is still long, with 55\% generally spending more than 40 minutes waiting for assistance. As for graph 4 , it was found that $96.7 \%$ of the participants would use the application in the academic environment, so they could perform other activities monitoring the progress of the queue, while $3.3 \%$ claim that this service would not bring no benefit. The main focus of the application would be for use in the academic environment, according to the survey the majority of the public would be willing to use the application for this medium. The demand for this type of service in colleges is high, especially during the student enrollment period, when there is a huge number of students waiting for assistance at the secretariat. It was verified in Graph 5 that $51.7 \%$ of the participants always feel like doing some activity while waiting in line, $40 \%$ claim that sometimes they are interested in doing another task and to complete $8.3 \%$ they never felt like doing another activity during the waiting time. It is observed that most people always feel, or have ever wanted to perform some other activity while waiting for the service in line. This time could be better used, as the user could follow the progress of the queue through the application and could do another task.

It was observed in Graph 6 that $86.7 \%$ of the participants never saw an application that offered this type of service, while $13.3 \%$ had already observed an application that presented the same proposal. It can be concluded that there is still a great demand for applications that will meet this type of need. The use of this resource in college would benefit a large number of students. From what has been presented so far, it can be concluded that the problem has been satisfactorily solved with space for future incremental implementations. Considering that the only reason we wait in person in an electronic queue is because of the fear of being called and, for not being on site, losing our turn, with the application we developed, users will be able to monitor their position from anywhere, that way, the primary problem is easily solved. Another possible problem that we thought about during the development of the application is the possible rejection of the application after the first use. The solution for this was to create an application as compact as possible, something that does not substantially affect the memory of the device, if it does not disturb the user on a daily basis, there will be no reason to discard the application. Thinking in a systematic way, we can also add automatic requirement checks before joining a queue, that way, neither the user wastes his time in a queue that will not help him nor the attendants will stop serving other people. If feasible, you can extend the use of the application to any and all electronic queues (banks, restaurants, hospitals, ...). But this is still a case that needs to be thoroughly investigated if such establishments would benefit from such a product.

\section{Acknowledgments}

We thank God, who gave us energy and benefits to complete this work. We thank the classmates who participated in the surveys. Finally, we would like to thank all the people who took part in yet another decisive stage of the course.

\section{Conclusion}

The aim of this work was to verify the feasibility of developing an application for managing academic queues. The results obtained satisfied the expectations of the team, as it was observed that there is a great need for the creation of this application, not only academic means, but also for banks, restaurants, hospitals. Based on research carried out both on interface design, as well as on the use of colors, the team was able to acquire greater knowledge in relation to the development of interface for applications, also using the 
usability criteria that aims to make the application, something intuitive and practical to different users.

\section{REFERENCES}

BERKMAN, Erick; HOOBER, Steven. Designing Mobile Interfaces: Patterns for Interaction Design. 1st ed. Califórnia: O'Reilly Media, 2011.

BUDIU, Raluca; NIELSEN, Jakob. Usabilidade Movel. 1. ed. Rio do Janeiro: Elsevier, 2014.

KOBAYASHI, Shigenobu. Color Image Scale. Kodansha Intern, 1991.

SANTA ROSA, J. G., \& MORAES, A. (2012). Avaliação e projeto no design de interfaces (1 ed.). Teresópolis, Rio de Janeiro: 2AB Editora.
SHARP, H., ROGERS, Y., \& Preece, J. (2013). Design de interação [recurso eletrônico]: Além da interação humano-computador ( $3^{\mathrm{a}}$ Ediçao ed.). (I. Gasparini, Trans.) Porto Alegre: Bookman Editora.

SOUZA, R. (2016). O que é UX Design? Acesso em 12 de janeiro de 2020, disponível em RAFFCOM: http://www.raffcom.com.br/blog/o-que-e-ux-design/

TEIXEIRA, F. (2014). Introdução e boas práticas em UX Design [recurso eletrônico]. Vila Mariana, São Paulo: Casa do Código.

TIDWELL, Jenifer. Designing Interfaces. 1st ed. Califórnia: O'Reilly Media, 2011. 